away the details.) For my taste, even more enjoyable than the stories is the language itself, which is thick with illuminating metaphors and amusing allusions of all sorts.

For a popular-level book, The Extravagant Universe is scientifically ambitious. Kirshner is not afraid to write about stellar spectra in some depth, to use plots of real data, and even to introduce an occasional simple equation. This is heartening, but I think that he might have spent more time trying to explain some of the basic physics at work. There are a number of places where a figure would have made things clearer; for example, although spectral lines are discussed frequently, there is no drawing of a canonical Bohr atom with an electron moving from one level to another. More surprisingly, in a book about the accelerating Universe, there is no plot of the size of the Universe against time, which would demonstrate the difference between accelerating and decelerating.

But these are quibbles, and most readers will learn a great deal from the book, and have fun in the process. The story being told is irresistible in its own right, and is related with verve and good humour. Nobody (or at least, very few people) expected that the Universe would be accelerating, and nobody (literally nobody) knows what dark energy is, or why it has the magnitude it does. Books like this one will help to inspire the next generation of physicists to ultimately answer these questions.

Sean Carroll is at the Enrico Fermi Institute, University of Chicago, Chicago, Illinois 60637, USA.

\section{The breath of life and death}

\section{Oxygen: The Molecule that Made the World \\ by Nick Lane \\ Oxford University Press: 2002. 384 pp. $£ 18.99$}

\section{Thomas B. L. Kirkwood}

The brilliant French chemist Antoine Lavoisier is credited with being the first to demonstrate the importance of oxygen to the world, showing in a famous experiment that the Holy Roman Emperor's diamonds were safe at high temperature provided that oxygen was excluded. Tragically, Lavoisier survived this flirtation with danger only to lose his head to the guillotine in revolutionary Paris on trumped-up charges of false accounting. Over the following centuries, oxygen, named for its 'acid-forming' powers, has become an element widely cherished for its life-supporting properties. We tend to see oxygen in a positive light, with superstar Michael Jackson allegedly spending his nights in an oxygen tent. Few other elements can claim this level of celebrity endorsement, but the truth is that oxygen is a mixed blessing. Anyone whose life has been marked by fire knows how dangerous it can be, and although we would quickly die without it, growing evidence suggests that oxygen plays a leading part in the ageing process. It is this balance of good and bad that makes oxygen such an interesting molecule.

Nick Lane's enjoyable and informative book would have us believe that "without the threat of oxygen toxicity, life would never have evolved beyond a green slime". Although we depend on it now, it seems highly likely that life first arose in the absence of free oxygen. Oxygen strips organic molecules of electrons and the earliest replicating biopolymers would have been defenceless against its attack. Thus, life began anaerobically and it was during the quiet aeons of early biological evolution that the first photosynthesizing bacteria began to secrete oxygen as a 'toxic' metabolic waste. Not for the last time, the planet's dominant life form made a mess of the environment. This environmental stress imposed a strong selection pressure and there emerged organisms that not only could withstand oxygen toxicity, but which found in this pollutant the source of a new energy supply. Oxidative phosphorylation was entrained in the service of a new breed oflife, and, in time, we came along.

In the first half of the book, Lane reviews in some detail the evidence for this role of oxygen in the evolution of life. Although he endorses the major elements of the conventional tale, he prefers a plot line that is relatively new. Instead of a primordial atmosphere made up mainly of methane, ammonia and hydrogen, Lane subscribes to the idea that 4 billion years ago the Earth's atmosphere consisted mostly of nitrogen, as today, with some carbon dioxide and water vapour, and traces of other gases including oxygen. The common view - and mine before reading this book - is that the impressive armoury of defences against oxygen toxicity in present-day organisms evolved to counter the growing danger as free oxygen accumulated in the atmosphere. The alternative, favoured by Lane, is that oxidative stress was known long before free oxygen became a hazard. A significant source of oxidative stress comes from the actions of ultraviolet radiation on water molecules. If life established an early presence in the radiation-exposed ocean surface, where water-splitting photosynthesis might most feasibly have evolved, cells must quickly have acquired potent antioxidant enzymes, such as catalase. So by the time atmospheric oxygen became a threat, the antioxidant defences were already partly in place.

Ultraviolet-induced oxidative stress remains a potent source of free radicals today, attacking any cell exposed to sunlight. Such stress is thought, for example, to play a part in age-related macular degeneration,

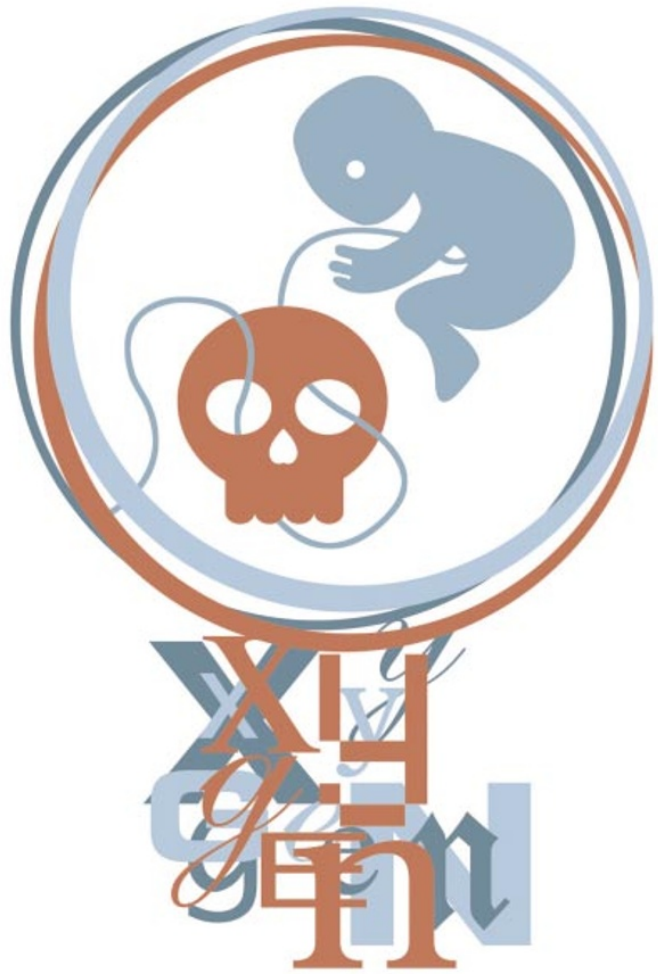

one of the most important causes of visual impairment in older people. This brings us to the second half of Lane's book, which is about oxygen's role in killing us. It is a pity that this substantial aspect of the book is not hinted at by the sub-title, because Oxygen presents an entertaining and cogent account of how oxidative stress fits into our rapidly expanding knowledge about ageing. Lane also describes work on degenerative conditions such as dementia, and explains with admirable clarity how an imbalance in the antioxidant defence system in people with Down's syndrome, who have an extra copy of the gene for superoxide dismutase, the enzyme which tackles the dangerous superoxide radical but makes harmful hydrogen peroxide in the process, contributes to an increased risk of Alzheimerlike symptoms.

The one shortcoming of the book, perhaps inevitable given its title, is that Lane pushes one molecular player into the limelight, to the exclusion of others, more than is right. The argument that oxygen is the molecule that made the world is hard to swallow, and oxidative stress is not the only agent that makes us age. Nevertheless, Lane presents a nicely crafted account of an important element's place in our lives. His book deserves to be read widely even if, in time, it must share space on the bookshelf with equivalent books on carbon, nitrogen, iron, and the rest.

Thomas B. L. Kirkwood is at the Institute for Ageing and Health, University of Newcastle upon

Tyne, Newcastle General Hospital,

Newcastle upon Tyne NE4 6BE, UK. 